Flavio Gewandsznajder

\title{
A Influência da Gestão da Informação no Processo Decisório da Previdência Social Brasileira: Um Estudo Exploratório
}

DISSERTAÇÃO DE MESTRADO

DEPARTAMENTO DE ADMINISTRAÇÃO

Programa de Pós-graduação em Administração 


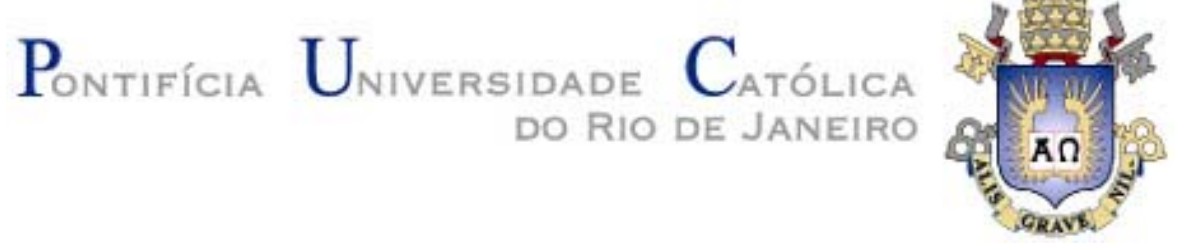

Flavio Gewandsznajder

\section{A Influência da Gestão da Informação no Processo Decisório da Previdência Social Brasileira: Um Estudo Exploratório}

Dissertação de Mestrado

Dissertação apresentada como requisito parcial para obtenção do título de Mestre pelo Programa de PósGraduação em Administração da PUC-Rio.

Orientador: Prof. Luiz Carlos Sá Carvalho 
Flavio Gewandsznajder

\section{A Influência da Gestão da Informação no Processo Decisório da Previdência Social Brasileira: Um Estudo Exploratório}

Dissertação apresentada como requisito parcial para obtenção do grau de Mestre pelo Programa de Pósgraduação em Administração de Empresas da PUC-Rio. Aprovada pela Comissão Examinadora abaixo assinada.

Prof. Luiz Carlos Sá Carvalho

Orientador

Departamento de Administração - PUC-Rio

Prof. José Roberto Gomes da Silva

Departamento de Administração - PUC-Rio

Prof. Sergio Proença Leitão

Departamento de Administração - PUC-Rio

Prof. Donaldo de Souza Dias

COPPEAD - UFRJ

Prof. João Pontes Nogueira Vice-Decano de Pós-Graduação do CCS 
Todos os direitos reservados. É proibida a reprodução total ou parcial do trabalho sem autorização da universidade, do autor e do orientador.

\section{Flavio Gewandsznajder}

Graduou-se em Engenharia Cartográfica pela UERJ em 1985. Cursou Análise de Sistemas na CCE/PUC-Rio em 1990, e MBA em Gestão Estratégica em Tecnologia da Informação pela FGV, em 2001. Como engenheiro, desenvolveu atividade profissional no INPE, nas áreas de cartografia e sensoriamento remoto. Atuou como analista de sistemas no Banco Performance e na Dataprev, a partir de 1990. Atua como gerente de desenvolvimento e manutenção de sistemas de informação desde 1994, sendo co-responsável pelo CNIS - Cadastro Nacional de Informações Sociais. Participa da formulação, implantação e integração de projetos de sistemas de informação na Previdência Social e governo federal.

Ficha catalográfica

Gewandsznajder, Flavio

A influência da gestão da informação no processo decisório da previdência social brasileira : um estudo exploratório / Flavio Gewandsznajder ; orientador: Luiz Carlos Sá Carvalho. - Rio de Janeiro : PUC-Rio, Departamento de Administração, 2005.

145 f. : il. ; $30 \mathrm{~cm}$

Dissertação (mestrado) - Pontifícia Universidade Católica do Rio de Janeiro, Departamento de Administração.

Inclui referências bibliográficas

1. Administração - Teses. 2. Gestão da informação. 3. Processo decisório. 4. Tecnologia da informação. 5. Sistemas de informação. 6. Sobrecarga de informação. 7. Previdência social. I. Carvalho, Luiz Carlos Sá. II. Pontifícia Universidade Católica do Rio de Janeiro. Departamento de Administração . III. Título. 
Para Ana e Iuri, pelo amor, carinho, apoio e paciência

Para meus pais, Martha e Simon, pela confiança e coragem 


\section{Agradecimentos}

Ao meu orientador Professor Luiz Carlos Sá Carvalho, pela confiança e motivação que viabilizaram a realização deste trabalho.

À Ana, pela revisão, paciência e persistência de todas as horas.

Ao Iuri, pela força de vontade.

Aos meus pais pela educação e otimismo proporcionados.

A todos os amigos e familiares que me apoiaram neste desafio.

Aos entrevistados pelo seu tempo, dedicação e compromisso em prol de uma organização salutar.

À Dataprev, pelos conhecimentos adquiridos e pelo tempo concedido para a redação final deste trabalho.

Aos colegas da Dataprev pela inestimável ajuda e compreensão.

Aos colegas da PUC-Rio.

Aos professores da banca examinadora.

Aos professores e funcionários do IAG.

À PUC-Rio pelos auxílios concedidos. 


\section{Resumo}

GEWANDSZNAJDER, Flavio. A INFLUÊNCIA DA GESTÃO DA INFORMAÇÃO NO PROCESSO DECISÓRIO DA PREVIDÊNCIA SOCIAL BRASILEIRA: UM ESTUDO EXPLORATÓRIO. Rio de Janeiro, 2005. 145p. Dissertação de Mestrado - Departamento de Administração, Pontifícia Universidade Católica do Rio de Janeiro.

A informação é considerada atualmente um recurso essencial para a sobrevivência e o desenvolvimento das organizações. $O$ advento de novas tecnologias de informação e comunicação possibilitou ofertar uma enorme quantidade de dados para uso de diretores, gerentes e gestores de negócios, em uma escala jamais imaginada há poucas décadas atrás. No entanto, o uso efetivo da informação envolve uma série de aspectos que não dependem apenas da quantidade e da tecnologia, mas de fatores que permitam capitalizar o seu valor, melhorando a qualidade das decisões nas organizações. Este trabalho busca conhecer melhor a relação existente entre os processos organizacionais de gestão da informação e sua influência no processo decisório de uma grande organização pública brasileira, a Previdência Social. Para tal, foram utilizados conceitos teóricos sobre gestão da informação disseminados por Marchand, Davenport e Checkland. A pesquisa foi realizada através de análise documental, observação participante e entrevistas semi-estruturadas, utilizadas para coletar as percepções e o comportamento relativo à tomada de decisão de diversos gestores das três instituições componentes da organização. A análise dos resultados revela aspectos que poderão contribuir para um melhor entendimento dos problemas de negócio e de informação vividos pela organização estudada, e aponta alternativas que tornem mais efetivos seus processos de informação, visando o aumento da qualidade dos serviços prestados à população brasileira.

\section{Palavras-chave}

Gestão da Informação; Processo Decisório; Tecnologia da Informação; Sistemas de Informação; Sobrecarga de Informação e Previdência Social. 


\section{Abstract}

GEWANDSZNAJDER, Flavio. THE INFLUENCE OF INFORMATION MANAGEMENT ON BRAZILIAN SOCIAL SECURITY DECISION-MAKING: AN EXPLORATORY STUDY. Rio de Janeiro, 2005. 145p. MSc. Dissertation - Departamento de Administração, Pontifícia Universidade Católica do Rio de Janeiro.

Information is nowadays considered an essential resource for the survival and development of organizations. The advent of new information and communication technologies made possible to offer an enormous amount of data for directors, managers and business executives' use in a scale never imagined a few decades ago. Nevertheless, the effective use of information cover several aspects which not only depend on quantity or technology, but also on factors that allow to capitalize its value, improving decision quality in the organizations. This work searches to know better the existing relation between the organizational processes of information management and its influence on decision-making of a large Brazilian public organization, the Social Security. In this way, theoretical concepts about information management spread by Marchand, Davenport and Checkland were used. The research was executed through documental analysis, participant observation and semi-structured interviews, all used to collect perceptions and behavior related to decision-making of several executives of the three institutions that make up the organization. The analysis of the results reveals aspects which may bring about a better understanding of business and information problems experienced by the studied organization, as well as pointing out alternatives to turn its information processes more effective, in order to aim at quality services increase granted to Brazilian population.

\section{Keywords}

Information Management; Decision-Making; Information Technology; Information Systems; Information Overload; Social Security. 


\section{Sumário}

1 Introdução 14

$\begin{array}{ll}\text { 1.1. O Problema } & 16\end{array}$

$\begin{array}{ll}\text { 1.2. Objetivos da Pesquisa } & 18\end{array}$

1.3. Relevância do Tema 19

1.4. Delimitação do Estudo 22

1.4.1. Contexto da Organização Estudada 23

2 Referencial Teórico $\quad 29$

2.1. Conceituação do Objeto Informação 30

2.2. Características da Informação Organizacional 35

2.3. Gestão da Informação 42

2.3.1. Histórico 44

2.3.2. Valor da Informação 49

2.3.3. Atividades e Papéis na Gestão da Informação 55

2.4. O Papel da Tecnologia da Informação 67

2.5. Processo Decisório - Uma Abordagem do Consumidor de Informação 72

2.6. O Fenômeno da Sobrecarga de Informação 82

3 Metodologia 86

3.1. Tipo de Pesquisa 86

3.2. Universo e Amostra $\quad 87$

3.3. Coleta de Dados $\quad 89$

3.4. Tratamento dos Dados 92

3.5. Limitações do Método 93

4 Análise dos Resultados $\quad 95$

4.1. Análise das Entrevistas 95

4.2. Análise Documental 117

4.3. Síntese dos Resultados 119 
5 Conclusões e Recomendações

6 Referências Bibliográficas

7 Anexos 135

7.1. Anexo I - Histórico da Organização Estudada 135

7.2. Anexo II - Roteiro de Entrevista 140

7.3. Anexo III - Calendário de Entrevistas 144

7.4. Anexo IV - Solicitação de Entrevista 145 


\section{Lista de tabelas}

Tabela 1 - Dado, Informação e Conhecimento 31

Tabela 2 - Atributos de qualidade da informação organizacional 41

Tabela 3 - Estilos de gerenciamento da informação 63

Tabela 4 - Crenças sobre a relação entre informação e tecnologia $\quad 69$

Tabela 5 - Tendências na tomada de decisões 77

Tabela 6 - Sistemas Administrativos x Centralização do

Processo Decisório $\quad 78$

Tabela 7 - Alternativas de Desenho Organizacional em uma

Organização Contingente $\quad 80$

Tabela 8 - Distribuição da Amostra por Instituição 88

Tabela 9 - Distribuição da Amostra por Linha de Negócio 88

Tabela 10 - Distribuição dos entrevistados por papéis e níveis $\begin{array}{ll}\text { hierárquicos } & 102\end{array}$

Tabela 11 - Resultados da avaliação sobre causas potenciais de problemas de informação na Previdência Social 108

Tabela 12 - Atributos de Qualidade da Informação mais Importantes para Tomada de Decisão 112

Tabela 13 - Atributos de Qualidade da Informação para Atendimento às Necessidades de Negócio 


\section{Lista de figuras}

Figura 1 - Dados x Informação x Conhecimento 34

Figura 2 - Classificação da informação segundo sua finalidade $\quad 36$

Figura 3 - Espiral do uso efetivo de informação nas organizações $\quad 56$

Figura 4 - Gerenciamento do ciclo de vida da informação 57

Figura 5 - Atividade de regulação de um sistema 60 


\section{Relação de Siglas e Abreviaturas}

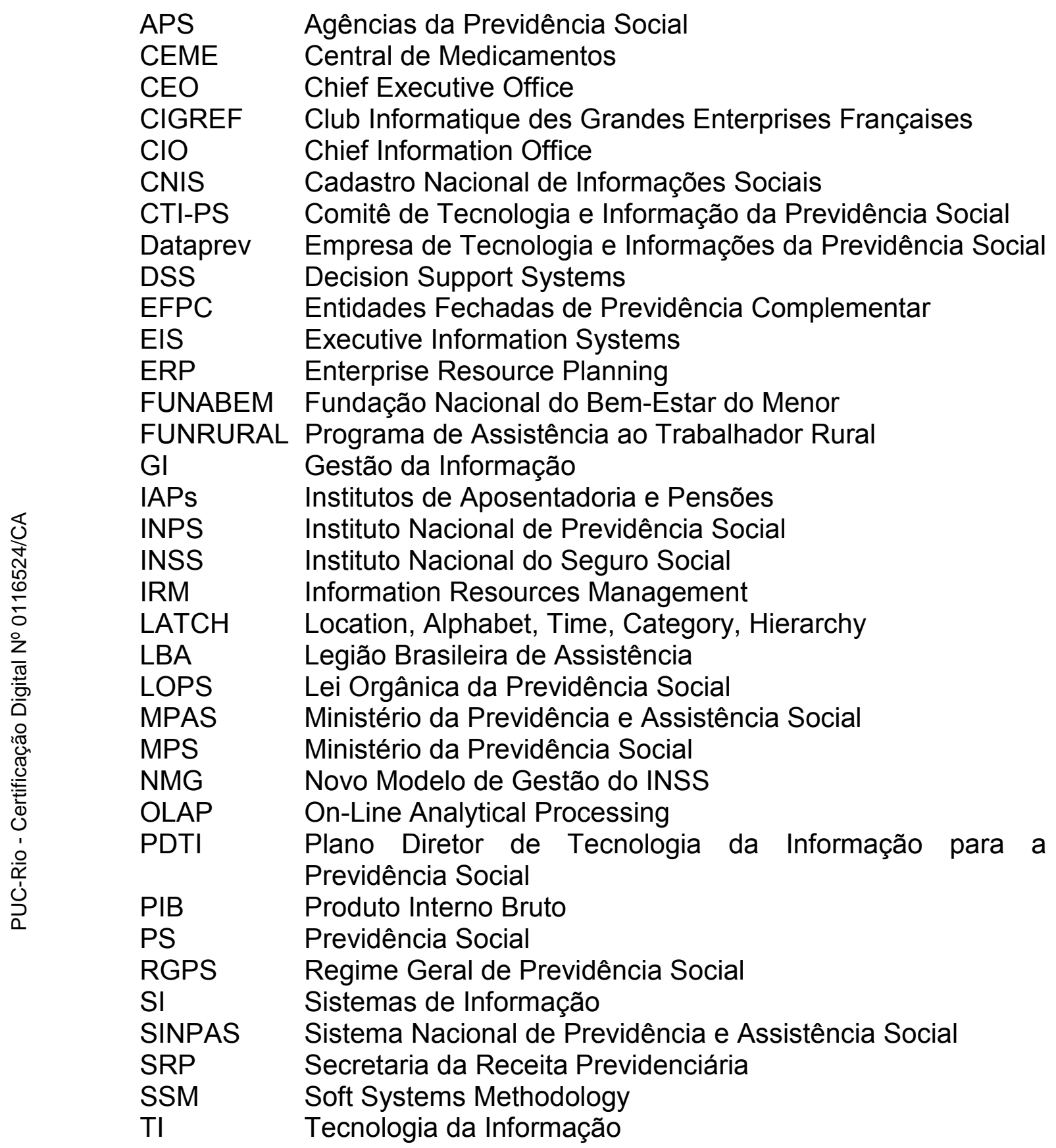


O mais forte instinto humano é comunicar informações; o segundo mais forte é resistir a elas.

Kenneth Grahame 